\title{
Environmental Safety in the Context of Sustainable Development of the Region
}

\author{
Yu. V. Khodkovskaya*, I. I. Fazrakhmanov, U. A. Nazarova \\ Ufa State Petroleum Technological University, Ufa,RussianFederation \\ *Corresponding author. Email: khodkovskiy@bk.ru
}

\begin{abstract}
The dynamic development of the world economy, the change of technological patterns, the search for highly effective ways of doing business for maximum consideration and satisfaction in the economic benefits of society have actualized the problems of irrational nature management, predatory treatment of environmental resources, and the man-made accidents and catastrophes that have become more frequent in recent years cause irreparable damage to the environmental safety of territories and regions. Along with dynamism, information, efficiency, environmental safety in the 21st century has been recognized as one of the key factors ensuring sustainable development of the region. The socio-ecological principles of the World Bank, the UN Green Economy concept, the European Green Course program, the Environmental Safety Strategy of the Russian Federation for the period up to 2025 and other important provisions indicate that the problem of ensuring environmental safety in the context of sustainable development of the region is not national, but international, global. The consequences of climate crises, weather anomalies, man-made accidents and disasters carry threats and risks to the entire planet, which confirms the importance of taking into account the ecological component in order to achieve sustainable development goals. Therefore, the study proposes a structurallogical model of interaction between the state, business, science and civil society to ensure environmental safety in a circular economy, the principles of its implementation. The necessity of applying the criterion "safety-qualitystability" is shown.
\end{abstract}

Keywords: region, ecology, safety, sustainable development, circular economy.

\section{INTRODUCTION}

Currently, the problem of ensuring environmental safety is of primary importance for modern society. Nature-intensive sectors of the economy with the help of highly efficient modern technologies extract maximum profit, environmental resources, its natural potential, disrupting the ecosystem. As world experience shows, the search for effective tools for sustainable development of the region in the face of growing competition in the markets of raw materials, capital, technologies, products increases the need not only for the economic, environmental and social development of the regions, but also raises the need to ensure security.

Despite the focus of national economies on improving the quality of life, increasing the well-being of the population, experts and analysts note the deterioration of the environmental situation in the world. The ranking of countries by the level of environmental pollution confirms the deterioration of the environmental situation in the world, for example, in countries such as Iraq, Peru, Azerbaijan, Italy, France, Belgium, etc., the pollution of territories and environmental damage to the world is increasing from year to year. Moreover, the widespread judgment about the harmful impact on the environment of exclusively nature-intensive industries as a result of human activity has been criticized in recent years. Alternative studies consider environmental safety as a multidimensional phenomenon, including climatic, landscape, resource conditions, biodiversity of territories [1,2], pointing to the inextricable link between sustainable development and environmental safety.

The concepts and strategies of the socio-economic development of regions, which are currently recognized as an essential component of sustainable development, define environmental safety as an indicator of improving the quality of life of the population. 
The focus on the development of the region indicates the importance of taking into account the criterion of "safety-quality-sustainability", the achievement of which will allow not only to formulate long-term goals for the development of the region, based on the priorities of national policy, but also to harmonize the interaction of all members of society.: the state, business, science and civil society as strategic partners in the formation of a sustainable geographically-oriented innovation ecosystem in the region.

Having studied the global and regional aspects of security, the practice of sustainable development of the region, the authors presented a structural-logical model of interaction between strategic partners to ensure environmental safety in the circular economy of the region and the principles of its implementation.

\section{METHODS AND MATERIALS}

Achieving high rates of economic growth, solving the problems of regional instability, the priority of national values in the face of global challenges and risks (sanctions, trade wars, coronavirus pandemic, etc.) have actualized the importance of solving the problem of sustainable development of the region, taking into account the environment. Despite the popularization of the ideas of a "green economy", "green energy", stimulation of "green investments" and "green innovations" in most regions of Russia and the world, nature-intensive sectors of the economy (oil, gas, coal) remain the driver of growth and development. Social entrepreneurship, projects for the creation of environmentally friendly industries remain unattractive for business due to low profitability, and, at times, nonrepayment of invested funds. Thus, ensuring environmental safety in the conflict of interests of the state, civil society and business can be interpreted as a manifestation of a stakeholder approach. The study of the essence of stakeholder value has shown that it is based on economic, social and environmental components [3]. From the perspective of the sustainable development of the region, the stakeholder value is one of the key goals of the formation of a humanized society, which is reflected in the environmental projects of the United Nations, indicating that "a sustainable future is linked to the preservation of the environment", in modern sustainable development strategies of foreign countries [4]. For example, in Sweden, Finland, Norway, one of the directions of sustainable development strategies is the formation of an effective climate policy, and economic, environmental, social and cultural factors are defined as indicators of sustainable development. The adopted European strategies and the concept of long-term development of the Russian Federation "Strategy 2030" indicate the need to take into account environmental safety in order to achieve "smart" economic growth (combining innovation and knowledge), sustainable economic growth (balanced development of the economy, ecology and social sphere), inclusive economic growth (strengthening integration processes in all spheres of human activity) that meet the needs of modern society [2].

The growing role of solving environmental problems in society has increased the need for its solution, which has caused the emergence of various forms and standards of corporate environmental responsibility at different levels of business [5], the formation of an environmental management system, the development of environmental awareness in society. Taking into account the ESG criteria (ecology, social development, management) of Kofi Annan, the principles of environmental motivation of business, foresight of the crisis consequences of business, balanced responsibility for environmental consequences, a number of researchers note the manifestation of constructive interaction between economic agents [6]. In this case, there is a dialogue between the state and business on financing projects based on public-private partnerships, subsidizing social entrepreneurship.

Analyzing the importance of the ecological component in the sustainable development of the region, the models "three-link spiral", "four-link spiral" and "five-link spiral" were studied [7, 8]. On the example of European countries (France, Denmark, Germany), the key goals of the European socially oriented market economy, the values of which are "green" investments, a socially conflict-free environment, and a balance of market efficiency and social justice, have been identified [2].

A number of researchers argue that the spread of international environmental standards and corporate environmental responsibility standards [9-11] in business stimulates the development of environmentally efficient business, environmental management in combination with the implementation of social projects [2]. Thus, the study of the role and place of the environmental component in the context of sustainable development of the region requires the formation of a model of interaction between the state, business, science and civil society to ensure environmental safety.

The research was carried out on the basis of a systematic approach, statistical data, reviews of analytical rating agencies, scientific publications and works on the research problem were analyzed.

\section{RESULTS AND DISCUSSION}

A critical review of scientific publications on the essence of environmental safety, its role and impact on the socio-economic state of the regions, the impact of business on the ecosystem of territories showed that an effective tool for ensuring environmental safety in the 
regions of Russia is legal responsibility: property, administrative, criminal, etc. According to the statistics of the regions of Russia, the main forms of legal impact on violators are reduced to fines and increased tariffs for the use of natural resources in excess of the established standards, man-made accidents. Moreover, compensation for damage occurs after the establishment of the fact of harmful effects on the environment, when the ecosystem is damaged, in many cases irreparable. In the subsoil user and other nature-intensive business in Russia, more than 4 billion tons of production and consumption wastes are generated annually, the bulk of which (over 90\%) is associated with the extraction of minerals. At the same time, only half of the waste is processed, the rest of the waste in the form of man-made objects or burials accumulates in the environment as toxic compounds and greenhouse gases, creating threats to the life and health of the population of the region [12]. According to experts from the Ministry of Natural Resources and Environment of the Russian Federation, in 2016-2020, there is an increase in environmental pollution by subsoil users and other nature-intensive businesses in the Irkutsk Region, Krasnoyarsk Territory, Lipetsk Region, Chelyabinsk Region, Orenburg Region, Omsk Region, Tyumen Region, Vologda Region. The listed subjects of the Federation do not belong to regions with a stable socio-economic position according to the 2020 rating. Nevertheless, the top 10 leaders of the rating of sustainable regions of Russia-2020 for several years include the constituent entities of the Federation the largest industrial centers with a raw material orientation - are the Khanty-Mansiysk Autonomous Okrug - Yugra, Krasnoyarsk Territory, Yamalo-Nenets Autonomous Okrug, Sverdlovsk Region, the ecological situation in which due to the active development of the mining and processing industry does not improve. In addition, a number of territories (the city of Norilsk Krasnoyarsk Krai, Gurovsky Municipal District Yamalo-Nenets Autonomous Okrug, Reftinsky City District - Sverdlovsk Region, etc.) are headed by the anti-rating of municipalities with the highest emissions of harmful substances into the atmosphere for 2020. Thus, despite the optimistic forecasts of the environmental development of the Russian Federation for the period up to 2030 to reduce the volume of emissions of pollutants from stationary sources per unit of GDP from 0.3 to $0.22 \mathrm{t} / \mathrm{million}$ greenhouse gases from 75 to $70 \%$ (compared to the 1990 level), generated waste of all hazard classes per unit of GDP - from 73.4 to 33.8 tons/million rubles, the number of cities with high and very high levels of atmospheric air pollution from 50 to 34 units [13], the problem of ensuring environmental safety remains unresolved even in those regions that demonstrate a stable socio-economic state and development. The problem of ecosystem pollution is aggravated by the impact of rapidly growing volumes of household waste: experts of Rosprirodnadzor note that by the beginning of 2021, 51.075 billion tons of industrial and consumer waste had been accumulated in Russia, and about 7 billion tons of waste were generated in 2020 alone. Therefore, it is necessary to create an infrastructure and a regulatory mechanism that meet the needs of society to create an environmentally friendly environment, ensuring sustainable development of the region.

A review of foreign practices for sustainable development of the countries of Denmark, Sweden, Canada, Germany, Norway and others showed that at the level of regions and territories, authorities aimed at increasing competitiveness and developing the entrepreneurial environment finance projects, setting priorities related to ensuring security. For example, in Denmark - Growth Houses, in Sweden - business incubators (National Incubator Program - NIP), in Canada - innovation hubs (Ontario's Medical and Related Science Discovery District), etc. In addition, in a number of countries, reserve funds have been created, the funds of which are used to eliminate the consequences of a negative impact on the ecosystem of territories, for example, in the USA - the Oil and Hazardous Substance Release Prevention and Response Fund, in the UK - Environmental Sensitive Areas, ESA, in Armenia - the Fund renewable resources and energy efficiency, in Uzbekistan - the National Fund for Ecology, Environmental Protection and Waste Management, etc. The emphasis of the business environment on economic, environmental, and communication security allowed not only to ensure the growth rate of GDP, but also to qualitatively change the business models used in the business environment. The modern trend of the economy of highly developed foreign countries has become innovative business models of energy conservation, environmentally friendly production, etc. - business models of a cyclic economy. High economic, environmental and social benefits in the regions were achieved using circular business models: Circular suppliers, Resources recovery, Product as a service. Circular business models are universal, and therefore find their application in a wide variety of sectors of the economy, from artisanal to high-tech. Regardless of the application, circular models optimize the entire value chain of creation, movement and storage. Undoubtedly, the transition to circular business models for the Russian economy is a path of rapid economic growth, increased sustainability, and security, including environmental security. However, the analysis of the effects and barriers from the use of circular business models abroad (China, Japan, France, Great Britain, etc.) indicates the need to take into account the peculiarities of economic development, the availability of resource potential, environmental characteristics, scientific and innovative potential within specific areas of development of society when developing regional strategies. Therefore, regional strategies for sustainable development of regions should 
be individual. Consequently, applying circular business models in Russia that ensure sustainable development and increase environmental safety, it is necessary to form a regional strategy taking into account the competitive advantages and disadvantages, as well as the existing potential of a particular region.

The analysis of the sustainable development of the regions of Russia made it possible to form a structural and logical model of interaction between the state, business, science and civil society to ensure environmental safety in the circular economy of the region: Fig.1.

The mechanism of interaction of strategic partners to ensure environmental safety in the circular economy of the region presented in Fig. 1 should be based on a number of important principles: 1) harmonization of the interests of all strategic partners to ensure sustainable development of the region; 2) openness and accessibility of information on monitoring the state of the ecosystem of the region; 3) environmental responsibility as the norm of life and conditions for the conservation and reproduction of the ecosystem of the region; 4) coordination of interaction of strategic partners in environmental management; 5) the integration of regional sustainable development strategies, taking into account the environmental component in the national strategy of the country; 6) the effectiveness of administrative tools in the field of ecology, economic stability and living standards; 7) optimization of business processes, taking into account the peculiarities of regional development, etc.

Currently, at the level of the regions of Russia, the key criterion for the degree of environmental hazard/safety is the National Environmental Rating of the regions of the Russian Federation, which takes into account the established facts of harm to the ecosystem of the region. Moreover, the retrospective ecological and economic analysis used as the basis of the rating is based on the developed unified mathematical model

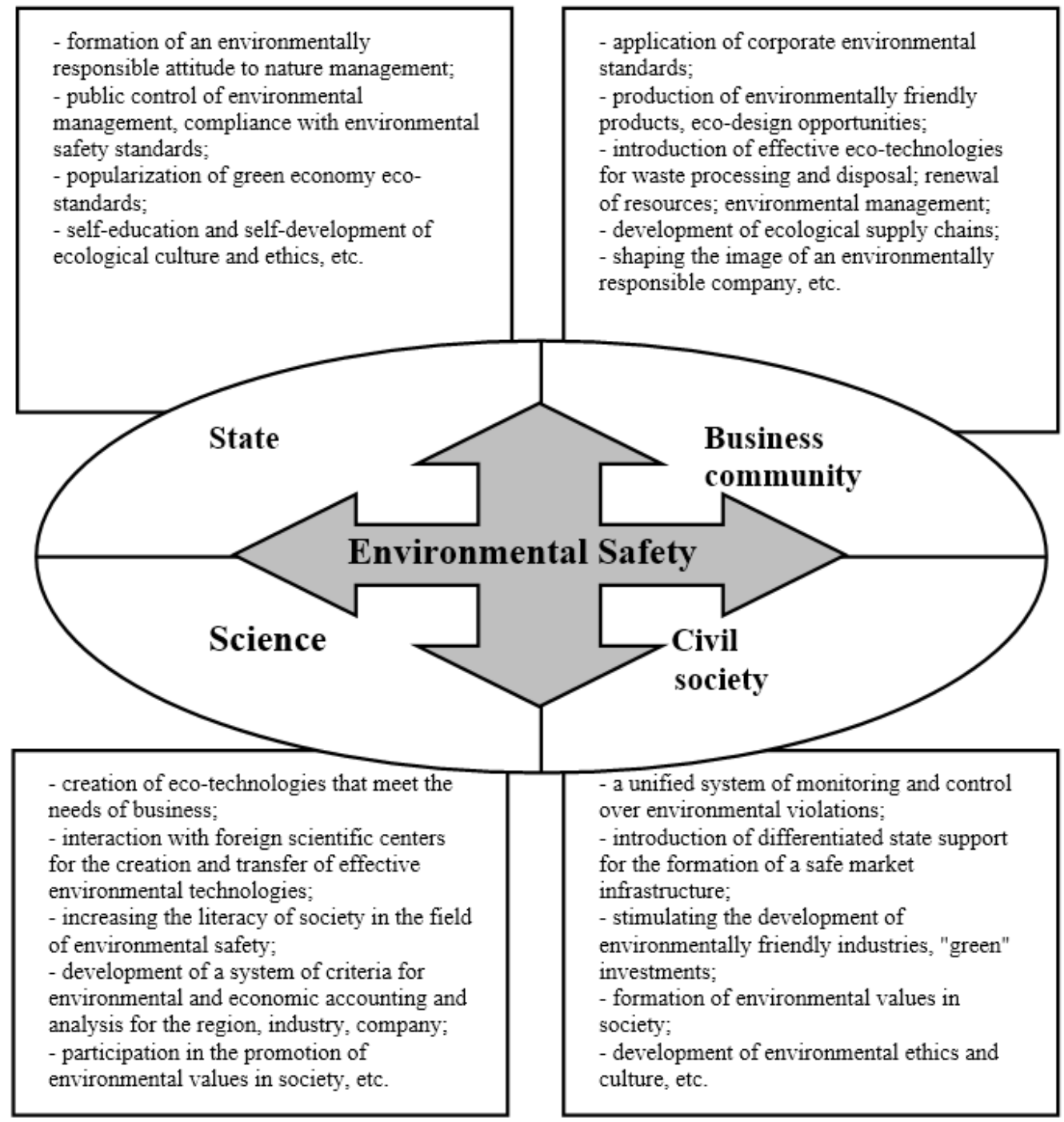

Figure 1 Structural-logical model of interaction of strategic partners to ensure environmental safety in the circular economy of the region. 
used for all surveyed regions of the country. Such an approach in assessing environmental hazard/safety is certainly formalized and takes into account only the impact on the environment of significant (significant) factors, without taking into account the potential of the region, the effectiveness of the mechanism for the prevention and administration of violations in the field of environmental management in the region, ensuring the conservation of natural resources in the region and their reproduction, the degree of impact of environmental risk on the quality of life of the population living in the region, etc. Thus, the applied model for assessing the environmental rating of the country's regions requires clarification: in particular, taking into account positive changes in ensuring environmental safety, the level of ecological and economic condition of the country's regions, real opportunities and prospects for overcoming environmental crises, calculating the assessment of losses of gross regional product due to irrational environmental management, forecasting environmental risks and developing measures to neutralize them. At present, in the scientific research environment there are quite a lot of works on the development of criteria for the sustainable development of regions, such as the theory of exponential growth of P.F. Verhulst, stability theory of A.M. Lyapunov, iterative criteria of Ya.E. Romm, the criterion "efficiency-sustainability" of $\mathrm{G}$. Manolov [2] and others, but the proposed criteria correspond to linear economics. For the circular economy of the region, the sustainability of development should be assessed and predicted taking into account the criterion "safety-quality-sustainability". The importance of applying the criterion "safetyquality-sustainability" is dictated by the society's focus on the progressive development of the ecosystem of the region, maximally satisfying the economic, social and environmental needs of society, without creating threats to the life of future generations [14]. The components of the criterion "safety", "quality" and "sustainability" embody the key goals of modern society, the achievement of which becomes possible only with the coordinated interaction of all strategic partners.

\section{CONCLUSIONS}

According to the results of the study, it should be noted the importance and relevance of studying the problem of ensuring environmental safety, since the emphasis on achieving environmental goals, conservation and rational use of national resources, the use of circular business models in the field of production and consumption create prerequisites for long-term sustainable socio-economic development of the region.

The main conclusions of the study are as follows: 1) the structural-logical model of interaction between the state, business, science and civil society to ensure environmental safety in the circular economy of the region allows coordinating the activities of all stakeholders to establish regional dominants reflecting the sectoral specifics of the economy, the production potential of an environmentally oriented business; 2) the principles of harmonization, openness, environmental responsibility, coordination, integration, efficiency, optimization of the structural and logical model are aimed at achieving the priority goals of sustainable development of the region, taking into account the environmental component in the strategic aspect. The implementation of these principles will provide a synergistic effect as a result of constructive interaction of all strategic partners at the regional level in the economic, environmental, social, institutional and other spheres of life; 3) The introduction of effective circular business models into the economy is a priority for nature-intensive regions, in which the problem of irrational use of natural resources, resource depletion, the growth of industrial waste, and emissions is especially acute. It is important for nature-intensive regions to use instruments of direct financing and budgeting of environmentally friendly industries, the involvement of private capital in the investment of resources in the "green economy". The selection of priority projects for financing should be carried out taking into account the environmental impact on the ecosystem of the region, assessing the prospective impact of environmental risks. The use of circular business models increases the competitiveness of the business environment, making it more attractive due to environmentally friendly industries for employees, at the same time, the problems of regional instability are solved; 4) achieving sustainable development of the region is possible taking into account the criterion of "safety-quality-sustainability", which most fully reflects the constipation of society in the circular economy of the region. The "security" component of the criterion takes into account the global and transboundary nature of threats to the region. The term "quality" measures the efficiency and greening of the entire value chain in a circular economy. The "sustainability" component is focused on the dynamic development of the region, the use of effective tools to influence the regional environment; 5) the formation of environmental funds both at the regional level and at the level of the business community, which will allow concentrating resources to achieve sustainable economic growth, investing funds in a green economy, environmental technologies for recycling and waste sorting. In this regard, it is necessary to improve the environmental insurance system by introducing compulsory insurance of environmental funds and environmental risks. It is also necessary to form a unified system for monitoring the state of the ecosystem of the region, providing all users with free access to information that reflects not only 
cases of harm to the environment, but also translates positive changes in the ecosystem of the region.

\section{REFERENCES}

[1] J. Mingjun, Ecological Safety Research, UN. IAELPS Press, p. 436 (2012) http://www.iescoiesco.org/Writable/Resource/books/b-pdf/researthzh.pdf.

[2] G. Manolov, D. Orlova, J. Khodkovskaya, et al., A Smart specialization strategy for sustainable development of regions. Strategy for intellectual specialization of sustainable development of regions. In: First conference on sustainable development: industrial future of territories (2020). DOI: https://doi.org/10.1051/e3sconf/202020808009.

[3] S.E. Apitz, A.G. Fitzpatrick, A. Mc Nally, et al., Stakeholder Value-Linked Sustainability Assessment: Evaluating Remedial Alternatives for the Portland Harbor Superfund Site.In: Integrated Environmental Assessment Management, 14(1) (2017) pp. 43-62. https://doi.org/10.1002/ieam.1998/.

[4] T. Brandsen, G. Ecchia, J. Eschweiler, et al. Cocreating a Social Innovation Research Agenda for Europe.Social Innovation Europe/EMES Network (2016) https://www.researchgate.net/.

[5] L. Zsolnai, Environmental ethics for business sustainability. In: International Journal of Social Economics, 38 (11) (2011) pp. 892-899. DOI: https://doi.org/10.1108/03068291111171397/.

[6] M. Oehmke, M.M. Opp, A Theory of Socially Responsible Investment. Swedish House of Finance Research Paper, 2020 (2020). DOI: https://doi.org/10.2139/ssrn.3467644.

[7] E. Carayannis, E. Grigoroudis, Quadruple Innovation Helix and Smart Specialization: Knowledge Production and National Competitiveness. In: Foresight and STI Governance, 10(1) (2016) pp. 31-42. DOI: https://doi.org/10.17323/1995-459x.2016.1.31.42.

[8] E.G. Carayannis, D.F.J. Campbell, Triple Helix, Quadruple Helix and Quintuple Helix, and how do knowledge, innovation and the environment relate to each other? In: International Journal of Social Ecology and Sustainable Development, 1(N1), pp. 41-69 (2010). DOI: https://doi.org/10.4018/jsesd.2010010105/.

[9] G. Dabelko, J. Barnett, Environmental Security (2019). DOI: https://doi.org/10.3316/JHS0301004/.

[10] E.A. Fomina, J.V. Khodkovskaya, I.A. Beloliptsev, D.V. Chuvilin, Challenges in Identifying FastGrowing Companies to Differentiate Government
Support Measures. Introduction: Challenges for Management, Economics and Law during a Transition to Industry 4.0, Walter de Gruyter GmbH, pp. 3-12 (2021). DOI: https://doi.org/10.1515/9783110654486-001.

[11] E.A. Fomina, J.V. Khodkovskaya, I.I. Fazrakhmanov, E.E. Barkova, Harmonizing the Interests of the State and Business in Stakeholder Management. Introduction: Challenges for Management, Economics and Law during a Transition to Industry 4.0, Walter de Gruyter GmbH, pp. 133-140 (2021). DOI: https://doi.org/10.1515/9783110654486-015.

[12] I. Joek-Kowalska, T.V. Ponomarenko, O.A. Marinina, Problems of interaction with stakeholders in the implementation of long-term mining projects. In: Notes of the Mining Institute, 232, pp. 428-437 (2018).

DOI: https://doi.org/10.31897/PMI.2018.4.428.

[13] Forecast of long-term socio-economic development of the Russian Federation for the period up to 2030 . http://www.consultant.ru/document/.

[14] United Nations Conference on Environment and Development. https://www.un.org/ru/documents/. 